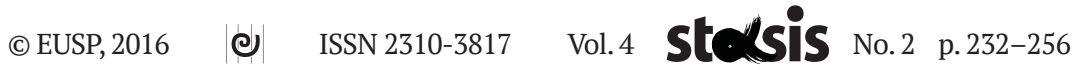

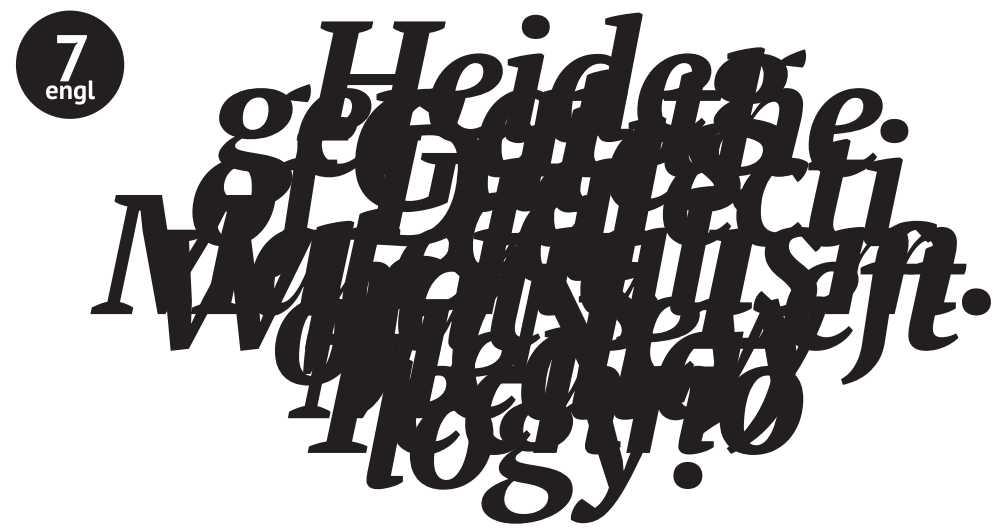

Katarina Peović Vuković

University of Rijeka, Croatia

\title{
Heidegger at the Gates of Dialectical Materialism. What's Left of (New Media) Technology?
}

\begin{abstract}
There are two theoretical anchors of this endeavor: the ontological perspective and the dialectical-materialist perspective. While dialectical materialism stresses the role of antagonism created by technological progress, the ontology of technology brings research to the question of essence, or specific technological (en)framing. This paper will try to prove that both the ontological and the dialectical-materialist perspective are substantial in the research of technology. Contemporary theory of new media rarely includes both theoretical principles, moreover the two perspectives are usually thought to be unrelated.
\end{abstract}

Keywords

dialectical materialism, Gestell, Heidegger, technology 


\section{Heidegger at the Gates of Dialectical Materialism}

There is no need to elaborate on the claim that technology is one of the essential phenomena of modern society. We can ask, however, whether this importance is accompanied by reflection, an understanding of its essence. Is it not, paradoxically, technological progress-the here and now of technology-that in the end blocks its phenomenological understanding? Emergent disciplines such as digital humanities or software studies promote the investigation of particular tools or software systems as instruments for some purpose. The question is whether this progress can be fully described in this neutral conceptual schema.

At first sight it seems that researchers are acknowledging the importance of technology. Software studies experts claim that researchers in the humanities can no longer work without essential technological skills such as simple computer programming, statistics, or data mining (Manovich 2011). Software studies experts are focusing on new digital tools, such as "big data" software, believing that those new tools can make a difference. Big data can be used as an example to elaborate problems with such epistemology. Big data is a format of collecting information that allows more approachable representation of large and complex data sets. In an article in Wired magazine from 2008, Lev Manovich announced that we are entering the "Petabyte age" of big data, where our ability to handle massive data sets will be challenged. Big data is presented as a tool for a new and indisputably better research strategy. Big data proponents claim that it works as a tool that allows us nothing less than "unlearning" what we know, unlearning concepts such as "style" or "period" (Manovich 2013: 9).

Of course, the obvious paradox lies in the fact that one cannot erase what is already known. Such a claim emerges from a belief that the missing element (new, unknown knowledge) is the element of knowledge constituting the paradigm as such (new knowledge). From a symptomatic point of view, this statement presents classical psychoanalytical aporia, functioning in the same way as, for example, the mechanism of fetishistic disavowal (Verleugnung), where the subject has not entirely forgot what he already knew (that the mother is castrated), but distorts the memory in order to produce new form of knowledge (Freud 2011: 4536). A trick of unconsciousness is exactly not to completely erase knowledge (complete erasing would be the case of "scotomization"), but to make a subject pretend not to know what he/she already knows. We can ask, however, whether inventing new tools for research has the same purpose as producing a fetish? Apart from their illogical, or even symptomatic auto-reflections, software studies researchers could be right, as with fetishists they certainly have a concrete object to lean on.

Is it not after all only a form of representation? Big data does represent things in a new way. The aim of digital humanities, according to its promoters, is to invent new ways of research or to approach culture in "a radically new way" (Berry 2011). But is it not, in the end, the final prob- 


\section{Katarina Peović Vuković}

lem of the research of technology? Frederic Jameson diagnosed that "capitalism itself lives in a perpetual present" (2004: xiv), which surely stands for digital humanities. Inventing a fetish in the form of big data, or another representative tool, does constitute an epistemological frame for the continuous present. Is it then the invention of a new tool/fetish here to solve the problem, or to stick to it and perpetuate it? At the same time, is it not possible if the subject is only pretending not to know what he/she already knows?

Redefining things anew is, after all, the most efficient tool of capitalism today, transforming non-profitable areas of life into new surplus value. In short, inventing things is not only a formula of fetishism but also of financialization. Marx described how this is the way in which capital deals with the constant tendency of the rate of profit to decline. In the third volume of Capital (1981), he explains how once capital is faced with the fact that it cannot intensify the exploitation of workers (by increasing working hours or reducing wages), it invents new models of increasing surplus value. Thus, the digital humanities' invention of new forms of representation must be seen not only as a fetishist gesture, but also a tendency of capital to generate new forms of profit. ${ }^{1}$

In such a fetishistic market-oriented model, technology is only a tool. The true motif of this pragmatic turn lies in the political-economic determinations that marked a larger turn in the humanities. It is not surprising to see that the understanding of technology's importance is being replaced by its mere usage, especially if we take into account that the humanities are increasingly orienting toward entrepreneurial and pragmatic practical knowledge defined by "concrete," practical, empirical outcomes. Aside from those aspects focused on in new media research, there is a greater problem with the part that is left out. Although presented as a milestone of modern society, technology is rarely approached as a specifically deep structure, an (en)framing, a Gestell in Heidegger's understanding of the term. Research limits itself with mere use of technology, a pragmatic application of technical tools with clearly defined empirical aims.

This paper thus presents an attempt to shift the research of technology from commonly used concepts and notions, toward fundamental questions of (en)framing, the imperatives of structure. The aim of such a questioning is twofold. First, to show how technology is not an autonomous tool, an abstract instrument that can, according to digital humani-

$1 \quad$ See, for example, Modern Political Economics. Making sense of the post-2008 world by Yanis Varoufakis, Joseph Halevi, and Nicholas J. Theocarakis where the authors elaborate on the dialectic of market-free zones and market reappropriation of those zones: "The result of this contradiction produces... an economic system that resembles a vast ocean of market activity punctuated by an archipelago of isles against which the mighty waves of commodification crash, but cannot fully overcome" (2011: 83). 


\section{Heidegger at the Gates of Dialectical Materialism}

ties, change our society, or bring something new, but that technology is already in relation to, inside and not outside, the social diagram. At the same time, the paper aims to show that technological structure is not something uniform and homogeneous, but a battlefield where confronted sides continually oppose each other. Conflicted examples within the technological matrix, such as free sharing or copyright infringements (that stand, of course, in relation to concrete technologies of the wide reproduction and distribution of the digital, meaning numerically represented artifacts), are suppressed, ignored, or interpreted only from the dominant ideological matrix. Such suppression will turn out to be the "logical" solution for an epistemological frame that aims at skill-oriented knowledge. This suppression plays an important role in promoting a vision of harmonious transformative technology.

At the same time, this paper will show that we are witnessing a stage of development in material productive forces where productive forces come into conflict with existing relations of production. As such, this moment presents the classical stage in the history of production forces that Karl Marx described as potentially revolutionary, since it is challenging existing relations in production (Marx 1904). The aim of this paper is to show how research of technology rests on non-conflictual examples and explanations of new media development and sticks to classical refrains such as communication, participation, and interactivity that are representing the social sphere as a mere result of changes in the field of technological progress. ${ }^{2}$ Blindness toward this dialectical process in which technology develops and changes through conflicts, antagonisms, and contradictions of capitalism will be approached as the symptom in the classical Freudian sense. Harmonious visions of a progress through simple progress of technological inventions are possible only with the suppression of conflictual cases, examples that don't fit the matrix.

In order to show how supposedly neutral technology closely relates to social diagram, political and economic agendas, social antagonisms, and emancipatory fights, this paper begins by proposing a twofold shift in the research of technology. The first can be described as a Heideggerian shift-a move away from a neutral vision of progress. The second is the shift toward dialectical materialism that points on conflictual moments and dialectical relations in social, political, or economic spheres, among different forces or groups. Such an epistemological marriage of Heidegger and Marx is not at all self evident. Contemporary Marxist philosophers too often escape the question of new media technology, not to mention their disinterest in Heidegger and his elaborations of technological Gestell. On

The same with its negative counterpart-common critique of devaluation of literacy and analytical thinking which supposedly took place as the result of technological changes. Both positive and negative visions start from the presumption that culture is a mere result of technological progress. 
the other hand, Heideggerians are often blinded by technological determinism and overwhelmed by the description of Gestell as omnipresent and determinate. As such, they are not in a position to see technology as a possible actor of revolutionary politics. Is it possible, then, to merge these two opposite endeavors-Heidegger's purely metaphysical perspective, on the one hand, and a dialectical perspective, oriented toward antagonism, on the other? Maybe even in Heidegger there exists an announcement of the positive notion of antagonism; especially at the end of his famous essay, "The question concerning technology" where he quotes Hölderlin: "where danger is, grows the saving power also..." (1977a: 316). ${ }^{3}$

\section{What Would Martin Heidegger Say About Technology Today?}

Can such research ever turn from its "regional orientation"? And is it in the position to elevate the "multiplicity of places belonging to the ready-to-hand" solutions (Heidegger 1962: 136) to a more fundamental level? Our first task is to summarize the importance of Heidegger's work that formulates fundamental research, since Heidegger elevates the question concerning technology to the level of ontological inquiry. First, in his well-known formula "technology is not equivalent to the essence of technology" (1977a: 287), he comprised a critique of actuality, the here and now of technology. What accompanies this problematic understanding of technology is preserved in the usage of the Aristotelian term actualitas (Heidegger 2012). Instead of technology as actuality, Aristotle's term includes a distinction between potentiality (the possibility of certain thing) and actuality (the exercise of that possibility), in other words a distinction between the ontic and the ontological. For Heidegger there is a parallel between the investigation of being and the investigation of technology. Relating being only to an ontic sense (and actuality) "ontology suppresses every possibility for a question of being” (2012: 25). ${ }^{4}$ As ontology and be-

3 There have been attempts to solve this problem and to engage Heidegger's elaborations with the public sphere. Habermas tried to move the representation of technology toward a more positive notion of technology, and notions that allow a socially oriented discussion on technology. The result is the notion of "communicative action" (Habermas, 1971: 81-128; 1981). However, while it shifted importance from technology to the public sphere, the notion of communicative action ended up as a global metaphor and a common understanding that eluded the technology from questions of the production and reproduction of social life. Habermas's public sphere functions as a sphere where conflicts can be resolved, and then later implemented on the matter of technology. However, communicative action does not include the material sphere of production and production forces as determinate forces in the last instance.

Such a conclusion derives from Being and Time where Heidegger defines "ontological inquiry" as "more primordial, as over against the ontical inquiry of the posi- 


\section{Heidegger at the Gates of Dialectical Materialism}

ing must be freed from the ontic, so the investigation of technology must be freed from the imperatives of actuality. Thus the first importance lies in pointing out the problems of ontical "actuality" that can also be traced in the epistemological frame of today's research.

The second important facet of Heidegger's work lies in the tracing of origins, or the essence, of technology. The maxim "technology is not equivalent to the essence of technology" (1977a: 287) also announces that the essence of technology cannot be limited to one technological skill, technological product, or technological procedure. Here, a wider perspective is proposed-technology is not only a tool, but a way of revealing (das Entbergen). For that reason, it is not enough to ask about the tool's purpose, its cause. To ask about purpose or cause means to understand technology as a pure instrument (Latin: instrumentum). The proper question is "What is an instrumental itself?" Or in other words, what is the technological relation to the deep structure of things?

Heidegger claims that, in a certain way, the Latin word causa blurred Western thinking and brought it to this instrumental understanding of technology. Instead of an instrumental understanding of causality, which has dominated the Western world since Aristotle's definition of fourfold causality (1977a: 290), the causa can be seen as the way of revealing, or a way of being responsible for something else (1977a: 290), a way of bringing something into appearance (1977a: 292). ${ }^{5}$ Following Aristotle's explanation of what this brings into appearance, Heidegger concludes that everything that was non-present becomes present in a form of bringing forth (in other words physis is always the poiesis). Thus, technology is not a means, nor an instrument for some purpose, but revealing, bringing forth, or aletheia. In Greek, the word aletheia stands for revealing. It is the word the Romans translated as veritas, or in English, truth. Thus, for Heidegger technology is nothing less than a truth. ${ }^{6}$

It may seem that both digital humanities and Heidegger move in the same direction since they insist on the historical importance of technol-

tive sciences” (1962: 31). Such division between positivistic sciences and philosophical sciences can be questioned, but still the regional orientation of sciences (both positive and philosophical) remains.

Aristotle listed four causes: causa materialis (the material, the matter out of which something is made), causa formalis (the form, the shape into which the matter enters), causa finalis (the end product, in relation to which it is determined in terms of its form and matter), and causa efficiens (which brings about the effect that is the finished product).

Here Alain Badiou's work comes to mind, since it serves as the missing link between Marx and Heidegger, through binding the being with the truth. This applies at least to Badiou's elaborations from L'être et l'évènement where he rewrites Heidegger's doctrine of truth, unbinds it from poetics and relates it to four generic procedures (Badiou, 1988: 22): love, art, science, and politics. 
ogy. Digital humanities see it as a sphere that can influence knowledge, pushing knowledge toward an unbiased understanding. For Heidegger, technology is nothing less than a way of revealing. However, their understanding of technological importance is substantially different. Although it worships technology, digital humanities do not approach technology as a fundamental structure, "a way of revealing," in Heideggerian terms, but as a simple tool, or instrument.

Therefore, the third influence that Heidegger's work has had on the research of technology is his strive to describe the fundamental structure of technology. And again, digital humanities seem to have the same affinity; it too describes technological tools. ${ }^{7}$ However, Heidegger sees technology as specific (en)framing, specific Gestell. His approach is at the same time more abstract from digital humanities' interest in software tools, and more concrete, since it addresses the deep structure of things. Heidegger's concept can be related to other philosophical concepts, such as the Deleuzian diagram (2006: 35) or the Foucaulian dispositif (1980: 194-228). It can be argued as to whether Heidegger discovered a Gestell of the modern world, and did he actually manage to describe contemporary society impregnated with the structure of technology? However, of the greatest importance is his pointing out the structure and the fact that this structure is not autonomous, but related to the wider social framework.

To conclude, modern interpretations of technology are characterized by actuality or a furious change that is presented as inner logic and the omnipresent value of things. The epistemology of technology today represents a form of blind belief in the power of neutral technology that can reform every humanistic type of research by the mere appropriation of technological tools. Epistemology should be challenged with a Heideggerian ontology. Such inquiry stepped out from easy ontical solutions and quick answers, and lifted the question concerning technology to the level of ontology. Heidegger disregarded simplistic instrumental notions and challenged them with analyses of deeper technological Gestell. In his recovery of the question as to the meaning of being, Heidegger established fundamental questions concerning technology. In drawing a distinction between the ontical and the ontological, between pragmatic existence and the meaning of Being, Heidegger founded a distinction that has survived until today: a distinction between ontological knowledge about technology, and ontical knowledge-the knowledge that is jailed in the pragmatism of actuality and the realm of individual objects.

However, following a Heideggerian path in full would be misleading, since Heidegger did not provide theoretical ground to analyze the relationship between the social sphere and technology, nor of the ways in

See for example Lev Manovich's study The Language of New Media (2002), which describes the basic principles of new media. 


\section{Heidegger at the Gates of Dialectical Materialism}

which we can interpret conflicts and antagonisms present within the development of concrete technology. Although Heidegger made a crucial move toward ontology, he left no space for a dialectical relation between consciousness and history, between technology and ideological, historically constructed knowledge about technology. ${ }^{8}$

Heidegger writes, "enframing is the gathering together which belongs to that setting-upon which challenges man and puts him in position to reveal the real, in the mode of ordering, as standing-reserve" (1977a: 305). As the final discovery of his ontology, Heidegger reviled the tendency of modern technology to "challenge" nature. Nature is standing-reserve (der Bestand), a resource to be disposable to humans. In that challenging of nature also lies the danger for human beings to be reduced to the same enframing, challenging as the standing-reserve. The example Heidegger offered could be described as enframing in the last instances; as it is the framing of the human. A forester is, whether he knows it or not, commanded and ordered not by himself, but by the profit-making lumber industry (1977a: 299). Not only nature but the human is set to supply energy that can be exacted and stored. Although the description of a dependent worker can be appropriate even today (it is a description of enframing of nature and man as standing-reserve), such dependence is not without conflicts, agencies, clashes of the conflicted groups. Also, Gestell as specific structure of modernity is a matter of conflict.

One cannot ignore the contemporary relationship between technological Gestell and structure of the world, the relation between the technology and processes of globalization, the flow of capital that puts nature and human beings in the position of a standing-reserve. Is it not exactly what is happening in a production of electronic devices in the Democratic Republic of Congo or China, where laptops and mobile phones are assembled, or where minerals needed for the manufacturing of those devices are extracted, where workers work twelve hours a day? And what about those working in Western countries who willingly erase the border between free time and working time? Workers are indeed treated as standing-reserve, a human resource disposable for other human beings. ${ }^{9}$ The Gestell described by Heidegger as a specific enframing of nature and man as standing-reserves could be accompanied with a more contemporary description of a

$8 \quad$ Later, Heidegger stands even more clearly by his position that leave no space for dialectics. In his lecture "The End of Philosophy and the Task of Thinking” (1977b), Heidegger follows Plato's division between the sophistic technê and the philosophical epistêmê, confronting technological thinking imposed by cybernetics with philosophical thinking. Thus he detects specific science, which has not proven its importance in the following years, as a sophistic carrier of instrumental knowledge and determinate element of the decline of philosophical thinking.

An essay written by Christian Fuchs, "Karl Marx and the Study of Media and Culture Today" elaborates this topic in detail (2014: 59). 
diagram of control. Gilles Deleuze described such a diagram in his essay "Postscript on the Societies of Control" (1992). Such a diagram supersedes Foucault's disciplinary societies from the eighteenth and nineteenth centuries that reached their height at the outset of the twentieth (Deleuze 1992). What accompanies today's capitalism is the control mechanism of modulation and "inseparable variations" that are forming a system of "variable geometry the language of which is numerical" (1992: 4). While disciplinary societies initiated the organization of "vast spaces of enclosure" (1992: 3), the individual never ceases passing from one closed environment to another, each having its own laws (family, school, factory, hospital, prison), modular control societies in which corporation stands as its symbol, work in a form of a spirit, a gas, perpetual metastability (1992: 4). A Western worker today willingly works more than eight hours a day, a fact that relates to contemporary technological Gestell. While the factory constituted individuals as naturally superimposed onto a capitalist, homogenized mass, the corporation breaks such homogeneity by constantly imposing "the brashest rivalry as a healthy form of emulation, an excellent motivational force that opposes individuals against one another and runs through each, dividing each within" (1992: 3-4).

The case of the Internet illustrates the importance of Hediegger (accompanied by Deleuzian insights), as well as its gap. On the level of Gestell, one cannot overlook the foundational element of postmodern society, a technological framework that is to be found on every level or in every structure-the structure of digital numerical language and the structure of a distributive network. In a pure technological sense, the TCP/IP protocol is the technology of decentralization that allows a structuring of the nonhierarchical network of hubs connected without hierarchical intermediation. The Internet is a network of "multiple nodes that can establish direct communication, without having to appeal to a hierarchical intermediary" (Galloway 2004: 15). However, reasons for establishing today's Gestell as an enframing that puts every subject in a position to interact, to participate and to communicate, lies in a political and economic realm, technology being only its expression. Even more fundamental, such a framework is not something fixed and final, but a substance on the move constantly, defined by social, political, and economic conflicts. Today, as ever, technology cannot be interpreted without a certain acknowledgment of political and economic conflicts.

The Internet is a social protocol, a diagram that can be found in different spheres of social life. At the same time, it is not a fixed, final solution for this concrete historical period. It is obvious that there are many conflicts and antagonisms on the matter of its structure as well as on the matter of practices within different social groups. This is why additional epistemological frames must be introduced. Marxism presents such a framework. It can introduce two additional distinct but related notions of today's Gestell. The first is a diagnosis of the character of contemporary 


\section{Heidegger at the Gates of Dialectical Materialism}

technology and its relation to political economy. The second is the inner inconsistency within technology and technological progress that works both as conflictual element blocking the traditional ways of production, and a constitutive element of new-established media Gestell. In short, it is important to elaborate on the application of dialectical materialism with regards the question concerning technology.

\section{Dialectical Materialism at Heidegger's Gates}

It was Friedrich Engels who used the term "materialist dialectic" (not dialectical materialism) in his Dialectic of Nature in 1883. Engels's work had an impact on Joseph Stalin's Dialectical and Historical Materialism, published in 1938 that was to become the official interpretation of Marxism and the orthodox view of the Marxist-Leninist Party. However, it is not to be confused with Marx/Engels' dialectical materialism. Although Stalin's pamphlet (1975) was written under the influence of Dialectics of Nature (1883) and Anti-Dühring (1894), written by Engels, it presents a reduction of Marxism to the level of doctrine of mechanical materialism. ${ }^{10}$ Stalin's dialectical materialism remained the external opposite of idealism as it saw the world as totally comprehensible. ${ }^{11}$

The work of Karl Marx is closely related to dialectical materialism. However this relationship needs to be elaborated upon. Marx developed his materialistic concept of history as a revision of the Hegelian dialectic. Hegel's dialectical logic is both a method of analysis and a recreation of the movement of the real, through a movement of thought (Lefebvre 2009: 29). ${ }^{12} \mathrm{~A}$ famous paragraph in Capital describes its method as turning

10 For an account of the evolution of a term "dialectical materialism," see for example Jordan, The Evolution of Dialectical Materialism (1967).

${ }_{11}$ Although, it must be noted that Slavoj Žižek sees Stalinist dialectical materialism as not completely detached from dialectical materialism, but a form of an "imbecile incarnation" of dialectical materialism that still relates a speculative identity of the highest and the lowest (realm of ideas and material base of the world). As such it is at the same time the universal ontology and its application to the special domain of society (Žižek 2008: 5).

12 The dialectical three-step process is a compound of thesis, antithesis, and synthesis. Thesis presents the first step of every opening, affirmation. Antithesis is a negation, while synthesis presents the abolition of what is particular in the first two steps. The role of synthesis in dialectical schema is to overcome the difference between the first and the second step. The first two "are annulled or sublated [aufge-hoben, which has no exact English equivalent] in the threefold aspect that their one-sided force is overcome, their relative meaning is preserved, and their original sense transmuted into a higher truth" (Windelband 1914: 861). Alexandre Kojève in his interpretation explains that thesis and antithesis are "overcome or annulled with respect to whatever is fragmentary, relative, partial, or one-sided in them” (1969: 181). 


\section{Katarina Peović Vuković}

the Hegelian dialectic on its feet. Marx writes that the Hegelian dialectic is standing on its head, which is why "[i]t must be inverted, in order to discover the rational kernel within the mystical shell" (1976: 103). It may seems like the dialectics, worked out in Hegel in an idealist form, in Marx starts from economic determinations and loses its abstract, idealist form. In his famous preface to A Contribution to the Critique of Political Economy, Marx summarizes a relation between Being and Knowledge, existence and consciousness: "It is not the consciousness of men that determines their existence, but their social existence that determines their consciousness" (1904: 11-12). Marx, however, demonstrated a dialectical relation between social existence and knowledge. Sartre writes how Marx demonstrated that "history is in development, that Being is irreducible to Knowledge and... he preserved the dialectical movement both in Being and in Knowledge" (1976: 23). Dialectical materialism is both the dialectical interpretation of reality, and the interpretation that sees determination (in the last instance) by the material world. As such, it presents a materialist conception of history with the Hegelian dialectic as method. It is important to note that although Marxian theory sometimes follows a straight division (at least between materialist reductionists and dialectical materialists), dialectic is already conserved in Marx.

Here, again, the term historical materialism can be used since historical materialism already treats ideas and social institutions as the superstructure of a material economic base, but at the same time holds dialectical method as fundamental. The often connoted opposition between supposedly concrete (Marxian) historical materialism and sublime dialectical materialism can be challenged through the opposition between abstract and concrete. Marx's categories are at the same time abstract, but only and "inasmuch as they are elements obtained by the analysis of the actual given content” (Lefebvre 2009: 76). For example, Marx elaborates use-value as concrete element, while exchange-value is an abstraction. Yet he also sees exchange-value as concrete since it is the starting point of an eminently concrete process: the market economy (Lefebvre 2009: 76).

Taking this into account, the question remains as to what would be the proper way to approach the relationship between technology as material production force and revolutionary ideas that emerge from contemporary superstructural conflicts? Dialectical materialism, although starting with a priority of matter over mind, maintains that the material basis is unstable and in constant change. Materialist dialectic is "a revolutionary dialectic," writes Lukács, precisely because it bears in mind that "the categories are but forms of being, conditions of existence" (1967: 10). Thus, in the case of new media technologies what also needs to be investigated are conditions, states, or processes, and not fixed tools or technological apparatuses.

If there is a difference between dialectical materialism and (vulgar) Marxism, there should be a difference in the approach to social antago- 


\section{Heidegger at the Gates of Dialectical Materialism}

nisms. Dialectical materialism does take into account conflicts and antagonisms, which nevertheless complicate simplified elaborations of the material base as an ultimate determinate force responsible for technological progress. Walter Benjamin in his "On the Concept of History" (1968) precisely describes the problems emerging from treating technological inventions as determinate forces of social change:

Nothing has corrupted the German working class so much as the notion that it was moving with the current. It regarded technological developments as the fall of the stream with which it thought it was moving. From there it was but a step to the illusion that the factory work which was supposed to tend toward technological progress constituted a political achievement (Benjamin 1968: 258).

The problem emerging from determinism is that it erases the relationship between progress and class struggle. Such a vulgar Marxist view that defines labor by relating it to an undisputed, unidimensional vision of positive technological and scientific development is something shared both by the public (common) view and the reductionist left (Benjamin criticized a stream in social democracy). Burdened with economic determinism, this stream sees labor as a necessity of progress, and progress as something natural and ultimately positive. At the same time, it is a classic misconception present in the wider understanding of technology and progress. Benjamin criticizes the Gotha program from 1875, Wilhelm Liebknecht and Ferdinand Lassalle, who wrote in this program that technological progress accompanied by labor presents "the source of all wealth and all culture" (cited in Benjamin 1968: 258). Benjamin takes the stand of Marx: "Smelling a rat, Marx countered," writes Benjamin. Benjamin quotes Marx: "the man who possesses no other property than his labor power" must of necessity become "the slave of other men who have made themselves the owners" (1968: 259). That basic law of the value form in capitalism guarantees that technology is not only a power of progress, but can also be an instrument in the hand of one class.

A dialectical approach to technology takes into account the (class) antagonism that is to be found at the very heart of the progress of production forces. On the matter of the Internet, that would mean to discover its inner dialectical logic while insisting on it as material technological base of society or in a pure Marxian sense as a force of production. Dialectical materialism provides ground for the understanding of technological development with an insight into its material determination. By inserting this view we are in a position to describe materialistic development of production forces ("machinery" is the term Marx uses) through the conflicts and antagonisms as crucial elements of such development.

Thus dialectical materialism must be implemented on the matter of new media technology. New media technology, treated as the material base 
of our society, is not harmoniously progressive, but dialectically split. It will be argued that such dialectical movement of technological progress is of crucial importance. However, if we replace the abstract notion of "matter" with a more precise determination of new media technology, as numerically represented data, it is in this context that "dialectical materialism" acquires a new meaning. New media technology being not the "raw" matter is a material substance historically transformed by the ideational activity of the subject. ${ }^{13}$ It must be noted that new media technologies are still material, although their material level is infinitesimal (at the level of microchips). However, this characteristic challenges dialectical-materialist interpretations of higher and lower, the relation of ideational activity of the mind to material substance, and transforms an understanding of the social determination of materialist existence, since now even that element in concept loses its raw form. This non-materiality will mark a definition of labor, making software programmers the equivalent of industrial workers, and making software non-material product of today's labor.

How does this Marxist analysis relate to Gestell? The contradiction that Heidegger traces between technology as a way of revealing and technology as a suppression of being (a way of human Gestell) is an inversed form of Benjamin's dialectical-materialist remark on technology. It is possible that Benjamin does not see the relation of technological Gestell to the social structure of the world. He only pinpoints technological determinism that lies beneath this common understanding of technological progress. Technological determinism indeed presents a common view on technology. However, there is a relationship between technology and the social sphere, although such a relationship is not deterministic. A deep diagram of the world is not a direct outcome of technology or progress. The crucial perspective should provide a dialectical relation between social elements and technological Gestell. In other words, Heidegger's interpretations should be accompanied by dialectical materialism.

\section{Social Media Theory. New Media Universality}

The fundamental problem of today's approach to technology is the same as Benjamin detected-seeing progress as neutral and undisputed, a positive force that can transform society. Is it not the same problem that relates digital humanities, as a progress-oriented entrepreneurial discipline, with socially and economically more profound theories, such as social media theory? Social media theory investigates how the material base of today's new media technologies is interested in social relations and social determinations. This way of describing techno-cultural changes in

13 Here I follow Artemy Magun's remark in personal correspondence (March 2016). 


\section{Heidegger at the Gates of Dialectical Materialism}

contemporaneity at first sight escapes easy determinations. Seemingly, it relates technological Gestell to the socio-political matrix. As an underlying presumption in Manuel Castells's description of informationalism as a technological structuring of the world, there exists the social and political determination of technology. Castells (2004) elaborates how not only technological inventions, but also social and economic factors determinate contemporary progress. He includes a profound elaboration of what he calls the "technological paradigm" that structures scientific knowledge and technological innovation. Technological discoveries play a significant, but not determining, role in a society, since they only enhance "the performance of each specific technology" (2004: 8). In other words, the technological paradigm is not something that was defined at the moment of discovery of a technological tool, but it is the conceptual pattern that sets the standard for the future performance (2004: 8).

However, the social theory of new media, including the work of Manuel Castells, falls under a different type of determinism. Although starting from almost opposite standpoints, similarly to digital humanities, social media theory comes to the conclusion that digital technologies and the Internet are constitutive tools of the dominant model of post-politics. The Internet is described as a universal tool for overcoming particularities of primary identities. Such a view is well elaborated in the now classic first volume of Castells's study The Rise of the Network Society. Here Castells offers the basic formula of opposition between "the Net and its abstract, universal instrumentalism, and the Self that is particular and historically rooted" (2000: 3). In such a context, the Internet is seen as a universal place where the instrumental mind predominates over the particularities of the geographically and historically determined logic of premodern society. Castells believes in technology as a major component of a "liberating power of identity" (Castells 2000: 4), such identity that would not accept any fundamentalism (2000: 4). He relates the IT revolution to the liberal spirit of 1968 that has the power to challenge all particularities (2000: 41). Once established, a dichotomy between the particular and universal (where particular identity is geographically determined, while universal identity is related to decentralized networks) become the standard formula of networked post-political society.

Pierre Lévy further describes the Internet as a "universal without totality," a place in which totality could not survive because the Internet includes "all people with their differences, and even with differences within themselves" (2001: 91). In his pioneering study, Cyberculture, originally published in French in 1997, Lévy claims that "the universality of cyberspace lacks any center or guidelines. It is empty, without any particular content. Or rather it excepts all content” (2001: 91). In his vision it is easy to detect behind it a modernistic concept of progress, where progress is something undisputed. It presents the modernistic project of rationalization active from Gottfried Leibnitz's concept of mathesis univerzalis 


\section{Katarina Peović Vuković}

and Max Weber's understanding of instrumental rationality. Lévy believes that cyberspace resonates with the Enlightenment and humanism because an "idea of cyberspace implicates all human beings by right" (Lévy 2001: 100, own emphasis added).

The Web 2.0 era intensified inventions aiming at such highly individualized usage of the Internet, providing social media theory with more examples of political universality. Thus, in his Communication Power from 2009 , Castells describes the emergence of a new era of "mass self-communication." Mass self-communication media are media such as "a video on YouTube, a blog with RSS links to a number of web sources, or a message to a massive e-mail list" (2009: 55). The difference between old mass media and new mass self-communication is that the second can potentially "reach a global audience," but at the same time the individual user is in control of the message (2009: 55). The production of the message is selfgenerated, the definition of the potential receiver(s) is self-directed, and the retrieval of specific messages or content from the World Wide Web and electronic communication networks is self-selected" (2009: 55). Although he is skeptical about defining the content and purpose of social change, Castells believes in a rise of mass self-communication that "enhances the opportunities" for democratic change (2009: 8). Such a framework sketches two opposed world-the one of traditional Gestell, a structure of traditional media, in itself centralized with a homogenized audience; and second, the universal place of the Internet, as a decentralized tool for the broader democratization of the public sphere. Although social media theory is free from the digital humanities' obsession with technological newness, their logic brings them to the same description of the Internet as a democratic sphere of communication.

Such a view relies on specific understanding of personal freedoms and human rights. The frame of both digital humanities and social media theory can be described through Alain Badiou's concept of "capitalo-parliamentarism" (2007: 27). It is a frame in which economy simply runs as neutral exteriority and stands as the ultimate principle of sociality, while personal freedoms and tolerance are leveled on the throne of indisputable value (2007: 27). Although social media theory, especially that of Manuel Castells, describes the social and economic determinations of technological Gestell, it does imply the same problematic capitalistic universe like the one present in the digital humanities worldview. What relates these two opposite endeavors is the understanding of the universal and particular where the decentralized space of digital media unquestionably offers the opportunity for transcendent differences in the inclusive matrix of the universal.

From such a viewpoint, technology is seen as a necessity whereas progress is understood as something natural, positive, and undisputed. Is it not the same idealization of progress for the sake of progress, as Benjamin described with Marx's successors? To challenge such a harmo- 


\section{Heidegger at the Gates of Dialectical Materialism}

nious vision of technological progress means to address Marx's work. Because, what a harmonious and non-conflictual approach does not encounter is the fundamental question of how the products of labor might benefit the workers (Benjamin 1968: 258). In other words, to challenge the neutral and instrumental vision of technology-that Heidegger challenged in his ontological approach to technology, means also to question progress itself as a harmonious and without any frictions. Benjamin wrote, "a critique of the concept of such a progression must be the basis of any criticism of the concept of progress itself" (1968: 261).

A critique of progress as undisputed benefit has nothing to do with conservative skepticism toward technology (although some leftist interpretations follow this path ${ }^{14}$ ). To challenge technological progress as neutral and instrumental means two things. First, it means to acknowledge progress and technological development as preformulated in a certain way. It is on the one hand a formation of technological Gestell, a structure that is first of all a way of revealing. Such a framework in modern society is further determined by something Heidegger did not include in his analyses - the capitalist way of production. Production is first of all formatted in order to produce commodities in a specific manner (defined by the law of the value), as well as to reproduce conditions of social life, in order to preserve social relations intact. Secondly, to acknowledge progress and technological development as a specific Gestell of late capitalism means to acknowledge that such progress is founded upon contradictions and antagonisms. Having in mind two aims, we are in the position to ask about the character of contemporary technological Gestell.

\section{Four Procedures of New Technological Gestell}

Is there not an idea of harmonious progress behind every common view on technology? For example, is it not an idea present in the gesture of beatification of Steve Jobs, CEO of Apple Corporation, who after his death became widely recognized as a technological prophet, a charismatic pioneer of today's technological design? Such a portrayal elides two facts: first, the capitalist way of production that formatted ([en]framed) Jobs's inventions and designs; and second, the conflicts present on the matters of such designs. It seems that all inventions were based on creativity and inspiration. In other (Marxian) words, such a portrayal sees

14 Žižek partially addressed this problem in his study First as Tragedy Then as Farce (2009), where he criticized leftist appeals for saving nature (for example Evo Morales's, then president of Bolivia), leveling capitalism with the "cancer" of Nature, instead detecting a class fight as central for political change. Žižek appeals to abandon all glib generalizations where a "critique of capitalism morphs into the critique of "instrumental reason'...” (2009: 97). 
Being as not determined by Knowledge, as it does not see a dialectical movement both in Being and in Knowledge. To see Steve Jobs's designs as neutral and instrumental means to ignore "the labor of untold thousands in Apple's factories, conveniently hidden from sight on the other side of the planet" (Tokumitsu 2013), but also to ignore the typical "structures of inequality and exploitation that characterize global capitalism" (Sandoval 2014: 344). At the same time, such misconception also ignores the dialectical movement by which Apple's technological standards are formatted, but also by which those standards are constantly haunted. Apple's patents particularly limit what can be done with technology, with its resolutely profit-oriented services such as iTunes and Apple Stores, or Mac OS. ITunes precisely illustrates a collision in capitalism between "(a) the inexorable forces of capitalism which commodify everything and anything in their wake, and (b) the infinite tenacity with which human nature resists quantification, mechanisation and, thus, full commodification." (Varoufakis, Halevi, and Theocarakis 2011: 83). ITunes emerged from the non-profitable practice of sharing audio and video material through a software platform. The crucial distinction between the profitable iTunes model and the Internet itself as a platform for sharing and the direct distribution of data packages is iTunes' imperative of surplus value. Live and vivid practices of DIY and pirate cultures present different answers to the same technological paradigm of the Internet. Differences between two cultures are consequences of deep conflict within capitalist society, and a new inventive task for emergent capitalism.

What challenges a common harmonious socio-cultural vision of the Internet as a tool of the post-political world are tensions and conflicts present in new media technologies, the cases that point to the incompleteness of the modernistic project of progress. There obviously exists a traumatic kernel of the Internet, which disturbs the idea of the distributive and horizontal tool for the democratization of society. Traumatic representations such as YouTube Ukrainian snuff video, 3 Guys and 1 Hammer from 2007 (the first video of a murder of a man), which is nevertheless a viral video and a product of amateur culture; or Tweeted suicides as with a high school student from 2011; or the web cam suicide of a French solider during a chat in 2011 on a health forum; all are opposing positive visions of the Internet. From the point of view of Castells's or Lévy's egalitarian perspective, such traumatic representations are to be seen as a distortions of the original idea. Such representations however are not conflicting the notion of universalism - the very existence of such representations proves the openness of the Internet as first a truly distributive/decentralized media. Instead of seeing them as particularities of otherwise harmonic virtual context, we should approach them as symptoms of deeper inconsistencies of supposed openness, the universality of the Internet and the project of democratization of public space, in other words symptoms of contemporary Gestell. 


\section{Heidegger at the Gates of Dialectical Materialism}

What such universalism serves is not a specific and particular vision or a point of view, but a truly open free-market economy. Although all perspectives can be included, there is only one exclusion, a symptomatic empty spot that cannot be questioned. It is the matter of profit, the only thing that must remain sacred. Is it not a post-political universalism comprised in a Facebook mission "to give people the power to share and make the world more open and connected"? The Internet does present an ideal universal symbolic-economic machine not because of its inconsistencies, but exactly because it is truly open. What remains undisputed however is not the level of openness, but the mode of political economy.

Confronting the universality of the Internet with its particularities sketches the Gestell of the new society. Although provoked by a capitaloparlamentarist idea of public space, new technologies show themselves to be less a harmonious public space and more a site of struggle. If there is an optimism that can be related to the Internet as protocolar Gestell of decentralized communication, then such optimism can emerge exactly from what seems to be a failure of the Internet, unpleasant examples. The Internet has opened one of the deepest conflicts within capitalism today. It is a conflict on the matter of the infringement of intellectual property rights. Since the Internet radically decentralized the production and distribution of information-when a user distributes any kind of data (visual, audio, textual), another user becomes an owner of that data. This distributive structure opened the conflict between several social groups and agents, but at the same time those conflicts resulted in capitalist emergent solutions.

Roughly, we can locate four procedures or social answers to the technological paradigm of decentralized Gestell. All forms of social answers are in dialectical relation to each other-they conflict with each other, but also neither of the forms are pure, calcified, or fixed, but each is dialectical in itself. First, there is an initial demand for accessibility of information-applying free software norms to various cultural artifacts (music, design, literature). It was a reaction of the free software movement that resulted in the demand for inclusive openness. Richard Stallman, a founder of the Free Software Foundation, simply reacted against the companies "natural right" to own software. Here progress is seen as the first principle of modern society, limited by the logic of proprietary software. Stallman, working at MIT in the early 1980s, decided to develop the non-proprietary software GNU, a version of the licensed Unix program. The GNU project promoted free use and modification of the software, as long as such modified versions were distributed under the same conditions. Open software norms later applied to various cultural artifacts: music, design, literature, etc. Stallman simply insisted on sharing because such an approach allows the maximization of progress. Such a procedure can be described as democratic pragmatism - it starts from understanding of technology as the public sphere where the pragmatic solution would be to allow the sharing of 


\section{Katarina Peović Vuković}

software for the purpose of progress. Such a view advocates broad accessibility but not in a form of revolutionary politics. It is a critique of unproductive forms or procedures, but not a critique of a profit-oriented model as such. It does present itself as agency of social justice, but only because free software has proved to be, for the time being, the most productive form of inventing and improving new technologies. Everybody has access, but also the opportunity to improve the technological tools. Although starting from the proprietary premises and not having any problem with the profit-oriented capitalist matrix, it turned to be a utopian and conflictual idea. It entered into a conflict first of all with the second procedure.

The second procedure is the one of the traditional industries-first of all the music and movie industries. This procedure initiated the long legal battle (with uncertain results) against piracy; cases such as the postponed SOPA and PIPA acts, which aimed to redefine the fundamental decentralized structure of the Internet and to reaffirm residual cultures and capitalist logic of centralized production and distribution. It is a gesture of preserving the world in the form that it had been at the moment of their rising. The second social procedure can thus be described as industrial conservatism, since it aims at blocking progress for profit's sake. As a conservative procedure, it enters the fight with all other procedures, while at the same time is the weakest form of procedure since today everybody agrees on the fact that profiting on industrially manufactured goods presents an atavism.

The third procedure is highly conflictual, it is a negation of copyright by pirate websites and platforms as well as individual subjects. It can be understood as a pure pleasure enjoyment principle of downloading cultural products (books, movies, software, pictures, photographs, video games). However, such a procedure creates the most brutal economic conflict within the existing order. At the same time, although it creates conflict within production in late capitalism, it does not necessarily present a revolutionary politics. On the contrary, pirates claim to be legalistic in their acknowledging the individual actors' (industries or authors) right to create profit. ${ }^{15}$ On the other hand, they claim to use the possibilities of the Internet as a different distributive channel than traditional mass media channels. The legal case against The Pirate Bay founders shows how they are only reacting to the possibilities of free distribution of content via torrent technology. However, there are several cases of copyright infringement where perpetrators were not only using the opportunities of a distributive network, but at the same time acted in an activist manner. Those gestures are mostly gestures in the defense of the public sphere, unrestricted communication and access to information.

15 See for example the documentary The Pirate Bay Away From Keyboard (2013) where Peter Sunde, Fredrik Neij, and Gottfrid Svartholm, The Pirate Bay founders, elaborate their standpoints. 


\section{Heidegger at the Gates of Dialectical Materialism}

Aaron Swartz's case functions as a point of contradiction. Swartz was an activist who made publicly available JSTOR academic journal articles. He was prosecuted with draconian penalty (on two accounts of wire fraud and eleven violations of the Computer Fraud and Abuse Act, charges carrying a cumulative maximum penalty of one million dollars in fines plus thirty-five years in prison). The prosecution led Swartz to commit suicide in January 2013. The case functions as a symptom of the Real, showing the real nature of singular universal-the particular inconsistencies within the rule itself. Is it not the act of sharing academic articles, at the same time an act of the pure openness, even in liberal sense, as the need for questioning every dominant paradigm, every position of the universal as relative (this is Karl Popper's argument on the openness of science simplified)? Swartz's crime was that he stuck to liberal-democratic principles all too literally. He did stick to The Universal Declaration of Human Rights, adopted by the United Nations General Assembly in 1948, Article 27, which states: "Everyone has the right freely to participate in the cultural life of the community, to enjoy the arts and to share in scientific advancement and its benefits." However, such cases (similar can be said for whistleblowers' cases) show that the libertarian idea of an open society (even in the form of rationalist bureaucracies) can be suspended at any time in the name of the market economy. ${ }^{16}$ Thus the third procedure can be classified as democratic idiotism, where idiotism is taken as a form of highly intellectual stupidity of people who simply miss the "hidden contextual rules" through which the big Other functions (Žižek 2012: 9). As a democratic gesture at its purest, it does not participate in the great symbolic order, since it ignores the democratic underside of capitalism.

And finally, there is a fourth procedure that can be described as emergent capitalist self-regeneration. One must be very careful not to limit the present conflict on the incongruity between industrial conservatives and materialist activism. Emergent industries (such as Apple) do not enter into the traditional arena. The legal battle against piracy, the postponed SOPA and PIPA acts, aimed to redefine the fundamental decentralized structure of the Internet, to reaffirm residual cultures, and to straighten

16 Book sharing that is taking place on open platforms is another example of deep antagonism. One of the first scandals on this matter was initiated by Gigapedia (with the Ifile platform) that has been an open library with more than 400,000 eBooks available for download. In 2012, academic publishers including Cambridge University Press, Elsevier, and Pearson Education, led by the Booksellers Association (Börsenveiren) and the International Publishers Association (IPA) organized action against copyright infringement as a criminal business, and brought down the sites. The activist community denounced academic publishers as the ones who truly acted as "the enemies of science” (Taylor 2012). Activists pointed out the fact that shooting down piracy sites was shooting down the horizontal networks for the distribution of knowledge. 


\section{Katarina Peović Vuković}

the industrial capitalist logic of centralized production and distribution. Such legal battles of industrial conservativism were not attacked only by activists of open culture, agents of the first and third procedures, but also, and most forcefully, by capitalist self-regeneration agents-Internet giants such as Google and Facebook. The symbolic moment took place on November 15, 2011, when a group of nine Internet and technology companies (AOL, Mozilla, eBay, Facebook, Twitter, Google, Yahoo, Zynga and LinkedIn) ran a full-page ad in The New York Times, stating: "We stand together to protect innovation.”

Such a procedure breaks with the traditional order in significant way. It is an illustration of what post-Gramscian leftists, such as Raymond Williams, but also Slavoj Žižek, describe as a logic of late capitalism-the need of capitalism to appropriate authentic cultures, which is only a way of straightening, and not negating the existing order. The examples are Apple products or the Facebook structure-where profit is based on the marketing model, the selling of information about users. The concept of the producer-consumer, or the "prosumer" (a term coined by Cristian Fuchs in 2014), describes a new profiting model where at the same time producers of content are its consumers.

\section{Conclusion}

One can see how imperatives of production of surplus value remains in a namely post-ideological, inclusive context. The dialectical confrontation of different solutions, possibilities and beliefs (to limit possibilities, transgress every profitable orientation, or to invent new ways of surplus value) do present the Gestell of contemporary society that is itself defined by technological openness, inscribed in a post-political worldview context. All the same, such a context is limited by profit, although redefined in new production-consummation matrix.

Now we can go back to dialectical materialism. Sartre elaborated that to suppose that materialist dialectic is true, "it must be proved that a negation of a negation can be an affirmation, that conflicts-within a person or a group-are the motive force of History, that each moment of a series is comprehensible on the basis of the initial moment" (1976: 47). On the matter of the Internet and the four procedures related to copyright infringement, one can see gaps in the positive elaboration of the Internet's universality-in Pierre Lévy's, Manuel Castells's or Lev Manovich's descriptions. Conflict and negation are driving forces of history, no matter what answer to copyright infringement we take as final. Would it be a limitation of its possibilities by industrial conservatism? Or (most likely), a redefinition of surplus value by capitalist emergent industries? Would it be third solution-revolution driven by contra-cultural groups, democratic idiotism that drives community toward potentially revolutionary con- 


\section{Heidegger at the Gates of Dialectical Materialism}

flict? Or, would it be the answer of democratic pragmatism, the production of useful tools within the matrix of copyright?

If the third answer emerges as a sort of a final solution (although there can hardly be something like a final solution), it will be compared to other revolutionary moments or “events” in Badiou's (1988) or Sarte's sense (1976). Such moments, as the Revolution of 1789 "required a truly abnormal and unpredictable set of immediate causes" (Sartre 1976: 16). Such unpredictable causes demand caution when approaching the matter of new media technology since there is no determinism.

The dialectical-materialist view could lighten the procedures of capitalist self-regeneration, a need for the appropriation of authentic cultures and practices by emergent models of capitalism, as a way of straightening, and not negating, existing ways of production. At the same time, it would focus on the conflict of copyright infringement as a conflict within existing production forces (and not outside them, in a form of disruptive piracy hacker culture that works autonomous of any rules of capitalist society). We can find all procedures conflictual within themselves already. A close examination of hacker or piracy culture would show that such a culture originates in pragmatic and profit-oriented solutions and not outside them. The history of open source, for example, would show how there is no political conflict present in open source solutions, although, consequentially, a conflict did emerge. One oft-repeated mistake is relating Richard Stallman's copyleft idea with some opposition political-economic ideas. Stallman already started from proprietary presumptions. More antagonistically, The Pirate Bay case shows how a group can have no political arguments against the present mode of capitalist production and reproduction of social realty, but purely uses the possibilities of new media technologies.

To conclude, there are two steps in the affirmation of negativity and the antagonism in the research of technology, particularly new media technologies. The first step would be to step away from a post-political vision of new media technologies, especially a vision of the Internet as a universal place without particularities. This step implies a questioning of the relation of the universal and the particular. It means to displace the difference "between the universal and the particular into the particular itself” (Žižek 2008: 5). By practicing the concrete universal, one confronts universality with its "unbearable" example, such is the case of copyright infringement. The second step would be to replace this empty universalism with antagonism as the constitutive force for revolutionary and emergent forms of production. Thus, the second step would also mean to see the revolutionary potential of the Internet not in the areas of safe postideological universalism, but precisely in the generated conflicts in the realm of political economy.

Accompanied with the Heideggerian Gestell, dialectical materialism would not stop at the gates of reading technological structure as dis- 


\section{Katarina Peović Vuković}

tributive and participatory technology. It would ask for symptomatic spots that are usually interpreted as particularities of technological universality of connectedness and participation. At the same time, symptomatic readings are not aiming at discouraging and denouncing the possibilities of universal connectedness and networking. On the contrary, pointing to those problematic spots that are usually discarded as unpleasant examples serves to show exactly how those conflictual elements of technology are the most useful in noticing the kernel behind social or political reality, and to detect the barriers for progress as, in contemporary capitalo-parliamentarism, are first and foremost the barriers of political economy.

\section{Bibliography}

Badiou, Alain (1988). L'être et l'évènement, L'ordre philosophique. Paris: Éditions du Seuil (Collection dirigée par François Wahl).

Badiou, Alain (2007). De quoi Sarkozy est-il le nom? Circonstances 4. Paris: Nouvelles Editions Lignes.

Benjamin, Walter (1968). “Thesis on the Philosophy of History.” In Illuminations, ed. Hannah Arendt, trans. Harry Zohn, 253-64. New York: Schocken Books.

Berry, David M. (2011). "The Computational Turn. Thinking About the Digital Humanities.” Culture Machine, Vol. 12. http://www.culturemachine.net/index.php/cm/issue/view/23.

Castells, Manuel (2000). The Rise of the Network Society: The Information Age: Economy, Society and Culture. Oxford: Blackwell Publishing.

Castells, Manuel (2004). "Informationalism, Networks, and the Network Society: A Theoretical Blueprint.” In The Network Society. A Cross-Cultural Perspective, ed. Manuel Castells, 3-46. Northampton, MA: Edward Elgar Publishing Limited.

Castells. Manuel (2009). Communication Power. Oxford: Oxford University Press.

Deleuze, Gilles (1992). "Postscript on the Societies of Control." October 59: 3-7.

Deleuze, Gilles (2006). Foucault [1986]. Minneapolis: University of Minnesota Press.

Engels, Friedrich. (1987) “Dialectics of Nature” [1894]. Marxists Internet Archive. https:// www.marxists.org/archive/marx/works/download/EngelsDialectics_of_Nature_ part.pdf.

Engels, Friedrich. (1987). “Anti-Dühring” [1894]. Marxists Internet Archive. https://www. marxists.org/archive/marx/works/download/Engels_Anti_Duhring.pdf.

Foucault, Michel (1980). “The Confession of the Flesh” (interview), in Power/Knowledge Selected Interviews and Other Writings, ed. Colin Gordon, 194-228. New York: Pantheon Books.

Freud, Sigmund (2011). "Fetishism” [1917]. In Freud Complete Works, ed. Ivan Smith, 4533-38. http://www.valas.fr/IMG/pdf/Freud_Complete_Works.pdf.

Fuchs, Christian (2014). "Karl Marx and the Study of Media and Culture Today." Culture Unbound, Vol. 6: 39-76 (Linköping University Electronic Press. http://www.cultureunbound.ep.liu.se). 


\section{Heidegger at the Gates of Dialectical Materialism}

Galloway, Alexander R. (2004). Protocol. How Control Exists after Decentralization. Cambridge, MA: MIT Press

Habermas, Jürgen (1971). “Technology and Science as ‘Ideology’.” In Toward a Rational Society, 81-123. London: Heinemann Educational Books.

Heidegger, Martin (1962). Being and Time. Trans. John Macquarrie and Edward Robinson. Cambridge MA: Blackwell.

Heidegger, Martin (2012). Four Seminars: Le Thor 1966, 1968, 1969, Zähringen [1973]. Trans. Andrew Mitchell and François Raffoul. Bloomington: Indiana University Press.

Heidegger, Martin (1977a). “The Question Concerning Technology.” In Basic Writings from Being and Time (1927) to The Task of Thinking (1964), 287-317. London: Harper \& Row.

Heidegger, Martin (1977b). "The End of Philosophy and the Task of Thinking.” In Basic Writings from Being and Time (1927) to The Task of Thinking (1964), 373-92. London: Harper \& Row.

Jameson, Fredric (2004). "Foreword” [1976]. In Critique of Dialectical Reason, Vol. 1, by Jean-Paul Sartre. Trans. Alan Sheridan-Smith, xiii-xxxiii. New York: Verso.

Jordan, Zbigniew (1967). “The Evolution of Dialectical Materialism.” Marxist Internet Archive. https://www.marxists.org/reference/subject/philosophy/works/en/jordan2.html.

Kojève, Alexandre (1969). Introduction to the Reading of Hegel. Lectures on the "Phenomenology of Spirit,” ed. Allan Bloom, trans. James H. Nichols, Jr. Ithaca, NY: Cornell University Press.

Lefebvre, Henri (2009). Dialectical Materialism. Minneapolis: University of Minnesota Press.

Lévy, Pierre (2001). Cyberculture [1997]. Trans. Robert Bononno. Minneapolis: University of Minnesota Press.

Lukács, Georg (1967). “History and Class Consciousness. Studies in Marxist Dialectic.” Trans. Rodney Livingstone. Marxists Internet Archive. https://www.marxists.org/ archive/lukacs/works/history.

Manovich, Lev (2002). The Language of New Media. Cambridge, MA: MIT Press.

Manovich, Lev (2008). “The Petabyte Age: Because More Isn’t Just More-More Is Different.” Wired, 23 June. http://www.wired.com/2008/06/pb-intro.

Manovich, Lev (2011). “Trending: The Promises and the Challenges of Big Social Data.” Manovich.net. http://manovich.net/index.php/projects/trending-the-promisesand-the-challenges-of-big-social-data.

Manovich, Lev (2013). "Looking at One Million Images: How Visualization of Big Cultural Data Helps Us to Question Our Cultural Categories.” Paper presented at the Digital Humanities 2013 conference, Hannover, 5-7 December 2013.

Marx, Karl (1904). A Contribution to the Critique of Political Economy. Trans. N. I. Stone, Chicago: Charles H. Kerr \& Company.

Marx, Karl (1976). Capital. A Critique of Political Economy, Vol 1. Trans. Ben Fowkes. London: Penguin.

Marx, Karl (1981). Capital. A Critique of Political Economy, Vol 3. Trans. David Fernbach. London: Penguin. 


\section{Katarina Peović Vuković}

Sandoval, Marisol (2014). “Alternative Media-Participation and Critique," Heathwood Press. http:/www.heathwoodpress.com/alternative-media-participation-andcritique-marisol-sandoval.

Sartre, Jean-Paul (1976). Critique of Dialectical Reason, Vol. 1. Trans. Alan SheridanSmith. London: Verso.

Stalin, Joseph (1975). Dialectical and Historical Materialism. Calcutta: Mass Publications.

Taylor, Mike (2012). “Academic publishers have become the enemies of science.” The Guardian, 12 January. http://www.guardian.co.uk/science/2012/jan/16/academicpublishers-enemies-science.

The Universal Declaration of Human Rights: 1948-2008. United Nations. http://www. un.org/en/documents/udhr.

Tokumitsu, Miya (2013). “In the Name of Love.” Jacobin 13 (January). https://www.jacobinmag.com/2014/01/in-the-name-of-love.

Varoufakis, Yanis, Joseph Halevi and Nicholas J. Theocarakis (2011). Modern Political Economics. Making Sense of the Post-2008 World. New York: Routledge.

Windelband, Wilhelm (1914). History of Philosophy. Formation and Development of its Problems and Conceptions, Book II. Trans. James H. Tufts. New York: Macmillan.

Žižek, Slavoj (2012). Less Than Nothing. Hegel and the Shadow of Dialectical Materialism. London: Verso.

Žižek, Slavoj (2009). First as Tragedy Then as Farce. London; New York: Verso.

Žižek, Slavoj (2008). The Parallax View. Cambridge, MA: MIT Press. 